All participants with an interest in the prevention of child maltreatment are invited. The session will be facilitated by Dinesh Sethi, (WHO Regional Office for Europe), Mark Bellis (Public Health Wales), and Dimitrinka Jordanova Pesevska (the former Yugoslav Republic of Macedonia).

\section{Aftermath of disaster}

\section{TUE W 5}

\section{EARTHQUAKE 2015 IN NEPAL, AN EXPERIENCE AT BIR HOSPITAL, KATHMANDU}

Ashok Ratna Bajracharya. Professor and Head, Department of Orthopaedics and Trauma, Bir Hospital, Kathmandu, Nepal

\subsection{6/injuryprev-2016-042156.218}

Background On 25 $5^{\text {th }}$ April 2015 Nepal experienced earthquake of 7.8 Rector scale followed by another one of 6.8 Rector Scale next day with epicentre near Kathmandu. More than 9,000 people died, 25,000 injured, 200 missing, 500000 houses collapsed. Big after-shock 17 days later on $12^{\text {th }}$ May, killed 300, injured 3000 people. Country's central Hospital, Bir Hospital located in Kathmandu is a hub hospital for disaster management; though damaged itself, yet it treated all victims brought here.

Methods All victims brought in immediately and later were triaged, resuscitated, damage control surgery followed later by definite surgery were carried out as per necessity. Records were kept. Challenging logistics and supply were managed in best possible way under the circumstances with aid from abroad later in kinds, man power. As the hospital was damaged too, all in-patients were evacuated to nearby open field. Triage was carried out in open spaces available. Makeshift operation theatres were put up and surgery began as existing ones were damaged too. Side by side institutional rehabilitation was begun too with help from volunteers. Several volunteers from abroad technical and non-technical also helped us a lot.

Results Between 25 April till 17 June 2015, total of 2574 victims attended this hospital. Of them 132 were dead, 1434 were admitted, 1135 underwent Surgery, 568 of Major and 567 of Minor category, 24 died in hospital while on treatment. Of surgery, most (568) were orthopaedic cases, followed by Polytrauma and General Surgery 299, Neurosurgical 39, Chest trauma 24, Burn and Plastics 9, and ENT \& Dental 7. Damage control surgery was performed on 40 victims. Of 190 Orthopaedic surgery, 101 were for Lower Limb, 69 for Upper limb, 20 for Spine and Pelvis. Mechanisms of injury included being buried in rubbles, trapped between heavy objects\& collapsed building, falling objects and panic fleeing.

Conclusions This Natural catastrophe struck least developing country Nepal causing huge loss of life and economy. Rehabilitation and reconstruction is challenging. Since forewarning technology is still unavailable, Hospital preparedness in Emergency program with regular drill is essential for us to perform better in such situation.

\section{ALLEVIATING AFTERMATH OF TERROR THROUGH A PSYCHO-SOCIAL PRO-ACTIVE MODEL FOR FOLLOW-UP}

Freja Ulvestad Kärki. Norwegian Directorate of Health, Oslo
Background In 22 July 2011 a lone wolf terrorist managed to massacre 77 people, mainly youngsters participating in a political youth camp at Utøya Island outside Oslo. To meet the situation characterised as a national trauma a major psycho-social intervention was developed and implemented under the stewardship of health authorities and through consultations with experts, other central stake holders and the exposed themselves.

Methods The intervention was a large-scale pilot targeting the exposed (survivors with families, bereaved with parents and siblings) through a municipality-based individual and collective psycho-social follow-up model. The watchful waiting principle was replaced by pro-activity in the services. The individual needs in the victims were to be monitored by a health professional three times during the first year after terror. Individual contact persons providing a long time follow-up were pointed out in the municipal crisis units. National week-end and county-wise one-day reunions were arranged for the bereaved and the survivors with families. A large capacity building exercise was initiated in order to increase the competency of psychological trauma reactions and conditions in all relevant services.

Results Even if the effect of the interventions on the trauma related conditions is hard to measure there is convincing evidence for the benefit of the pro-active model as well as the benefit of the collective interventions, communicated by the service users themselves. The pro-active principle was embraced by all the exposed as were the national week-end gatherings for the bereaved. 99\% of the latter evaluated the collective intervention as a good or very good help in their grieving process.

Conclusions Even if it is very difficult to evaluate the effect of the intervention model in terms of reduced symptom load in the exposed, pro-activity should be considered as one of the guiding principles in assessing the psycho-social needs of the exposed in major incidents in the future.

\section{The European Injury Data Base (IDB)}

\section{TUE W 6}

\section{THE EUROPEAN INJURY DATA BASE: SUPPORTING INJURY RESEARCH AND POLICY ACROSS EUROPE}

${ }^{1}$ Samantha Turner, ${ }^{1,2}$ Ronan A Lyons, ${ }^{3}$ Wim Rogmans, ${ }^{4}$ Rupert Kisser, ${ }^{5}$ Bjarne Larsen, ${ }^{6}$ Huib Valkenberg, ${ }^{7}$ Dritan Bejko, ${ }^{8}$ Robert Bauer, ${ }^{8}$ Monica Steiner, ${ }^{9}$ Gabriele Ellsaesser. ${ }^{1}$ Far Institute Swansea University, Medical School, UK; ${ }^{2}$ Public Health Wales NHS Trust, UK ${ }^{3}$ Eurosafe, The Netherlands; ${ }^{4}$ Eurosafe, Austria; ${ }^{5}$ National Institute of Public Health, Denmark; ${ }^{6}$ Consumer Safety Institute, The Netherlands; ${ }^{7}$ Luxembourg Institute of Health, Luxembourg; ${ }^{8}$ Austrian Road Safety Board, Austria; ${ }^{9}$ State Office of Environment, Health and Consumer Protection, Germany

\subsection{6/injuryprev-2016-042156.220}

Background Although various injury data sources exist in Europe; many lack sufficient size, scope, detail or comparability, to support injury prevention research or policy development. Emergency department (ED) records offer one of the most comprehensive sources of injury data; however, heterogeneous hospital data collection systems prevent comparative analyses between countries.

Methods As part of the Joint Action on Monitoring Injuries in Europe (JAMIE) project, and now the BRIDGE-Health (BRidging Information and Data Generation for Evidence-based Health Policy and Research) development; the European Commission (EC) funded the development of a standardised European Injury Data 